Author Accepted Version. Final version published as: Temple, J. B., Rice, J. M., $\&$ McDonald, P. F. (2017). Mature age labour force participation and the life cycle deficit in Australia: 1981-82 to 2009-10. The Journal of the Economics of Ageing, 10, 21-33. 


\title{
Mature Age Labour Force Participation and the Life Cycle Deficit in Australia: 1981-82 to 2009-10
}

\begin{abstract}
With inexorable population ageing, successive Australian governments have sought to implement policies, on both the production and consumption side, that place a greater onus on older citizens to be financially self-sufficient as a means of offsetting costs due to ageing. Over the previous 30 years, a time of considerable labour market growth and policy change, mature age labour force participation increased significantly in Australia. In this paper, we utilise the National Transfer Accounts methodology to examine the impact that the increases in mature age labour force participation have had on the Life Cycle Deficit - the difference between what age groups consume and what they produce through their own labour. We expected and found that the age entering the life cycle deficit is strongly influenced by changing patterns of mature age labour force participation. Both cross-sectional and cohort analyses show that over this 30 year time horizon, the ages at which the life cycle deficit moves from positive to negative territory and vice versa have gradually increased over time. The growth in mature age labour force participation since the turn of this century has led to large increases in mature age labour income, the most important effect of which appears to have been a substantial increase in private saving by mature age Australians. Implications of a recent slowing in mature age labour force participation in Australia are discussed.
\end{abstract}

Keywords: Ageing; Economic Life Cycle; Labour Force Participation; National Transfer Accounts. 


\section{Mature Age Labour Force Participation and the Life Cycle Deficit in Australia:}

1981-82 to 2009-10

\section{Introduction}

Given inexorable population ageing, the economic roles of Australians of all ages, but particularly those of retirement age, have been central to many policy questions about Australia's economic future. Policy changes have occurred over previous decades on the production and consumption side to offset potential costs of population ageing in Australia. Examples of this include policies to encourage or support mature age labour force participation (e.g., the experience+ training package) and policies to reduce public expenditure on this growing demographic (e.g., increasing the eligibility age for the Age Pension).

These policy changes have been made in a period of economic prosperity in Australia, driven by significant increases in population, productivity and labour force growth. During this period, mature age labour force participation has also increased considerably. At the turn of this century, $47 \%$ of $60-64$ year old males and $9 \%$ of those 65 and over were in the labour market, compared with $63 \%$ and $17 \%$ today. For females, the results are even more marked. In 2000 , only $21 \%$ of $60-64$ year olds and about $3 \%$ of those aged 65 and over were in the labour market. Today, these figures are $49 \%$ and $9 \%$ respectively (ABS, 2017).

Over the past 30 years, Australia's labour supply has grown considerably during a time when the economy was geared to a rapid increase in labour supply. The key drivers of this growth, the full entry of the baby boom generation into the labour force (today's mature age workers) and very large increases in female labour force participation rates, will not influence future labour supply to any great extent (Temple and McDonald, 2008). Even with very high levels of migration by historical standards, in the next 30 years, the rate of growth of labour supply is projected to decline in Australia. This constraint comes at a time when both labour demand and the speed of population ageing is projected to increase significantly (McDonald and Temple, 2010). 
With these demographic and economic changes on the horizon, an understanding of the production and consumption behaviour of all Australians, but mature age Australians in particular, is timely. In this paper, we utilise the National Transfer Accounts (NTA) methodology to examine the impact that the increases in mature age labour force participation have had on the Life Cycle Deficit - the portion of the life cycle in which individuals consume more than they produce - over three decades from the early $1980 \mathrm{~s}$.

The remainder of this paper is structured as follows. First, we describe the overarching conceptual framework and the data, methodology, and techniques employed in the Australian NTA. We briefly discuss recent increases to mature age labour force participation, before detailing the life cycle deficit over the period 198182 to 2009-10, and its constituent parts (consumption and labour income). Then we discuss the changes in reallocations necessary to fund the life cycle deficit over this period. We conclude with a discussion of the role of mature age labour force participation on the life cycle deficit and directions for future research.

\section{Conceptual Framework}

The purpose of the Australian NTA project is to document the economic life cycle through the NTA system. The economic life cycle relates to the age-related patterns of consumption and labour income that are associated with the life cycle of education, work, and retirement. Specifically, the Australian NTA provides estimates of the economic flows across ages that arise from differential age-specific consumption and production profiles.

The Australian NTA project forms part of a large international project with research teams producing accounts covering over 80 countries in the Asia-Pacific, Americas, Europe and Africa. For a detailed overview of the theoretical basis of the NTA system, as well as detailed descriptions of methodology and cross-country comparisons, see Lee and Mason (2011a, 2011b), UN (2013), and the international National Transfer Accounts website (www.ntaccounts.org). 
Briefly, the full NTA specification is based on the following identity:

$y^{l}+r(K+M)+\tau_{g}^{+}+\tau_{f}^{+}=C+I_{K}+I_{M}+\tau_{g}^{-}+\tau_{f}^{-}$.

Given inflows consist of:

labour income $\left(y^{l}\right)$,

the returns to capital $(r K)$

the returns to land and credit $(r M)$

and transfer inflows from the public sector $\left(\tau_{g}^{+}\right)$and the private sector $\left(\tau_{f}^{+}\right)$.

Conversely, outflows consist of:

consumption $(C)$

investment in capital $\left(I_{K}\right)$

investment in land and credit $\left(I_{M}\right)$

and transfer outflows to the public sector $\left(\tau_{g}^{-}\right)$and the private sector $\left(\tau_{f}^{-}\right)$.

This identity holds for individuals as well as aggregates of individuals, including age groups and the population as a whole. It also holds for a range of time periods. It applies, for example, whether the focus is on an age group's experience during a particular year or on an age group's experience as it ages over the course of a decade.

Designating asset income by $y^{A}$, assets by $A=K+M$, and saving by $S=I_{K}+I_{M}$, and rearranging terms yields the key elements of the NTA. The difference between consumption and labour income is the life cycle deficit.

$$
\underbrace{C-y^{l}}_{\text {Lifecycle deficit }}=\underbrace{\underbrace{y^{A}-S}_{\text {Aset reallocations }}+\underbrace{\tau_{g}^{+}-\tau_{g}^{-}}_{\text {Net public transfers }}+\underbrace{\tau_{f}^{+}-\tau_{f}^{-}}_{\text {Net private transfers }}}_{\text {Age reallocations }}
$$

The life cycle deficit is the difference between what age groups consume and what they produce through their own labour. As such, we can expect the timing of the life cycle deficit to be strongly influenced by changing patterns of mature age labour force participation. The deficit is offset through a variety of age-based reallocation mechanisms: private transfers (for example, parents purchasing goods and services for their children), public transfers (for example, public age pensions and publicly 
provided education and health services), asset income, and savings. The life cycle deficit is equal to total age reallocations and, as such, is an indicator of the extent of the reallocations between age groups within a particular economy

It is important to define the measures of consumption and production that are included as constituent parts of the life cycle deficit in the Australian NTA framework. In this framework, consumption is comprised of public and private consumption on items such as education, health, housing, and childcare (Table 1).

\section{$<$ TABLE 1 ABOUT HERE $>$}

In the NTA framework, labour income consists of labour earnings inclusive of fringe benefits, and self-employed labour income (Table 1). For each of these broader concepts, there are a range of detailed NTA account items. Tables 2-3 display the detailed account items included in the Australian NTA for the economic life cycle (generating the life cycle deficit) and also for public age reallocations and private age reallocations (which fund the life cycle deficit). Further information about these account items can be found in Rice, Temple, and McDonald (2014).

\section{<TABLES 2 AND 3 ABOUT HERE>}

\section{Data and Methodology}

\section{Methodology}

Within the framework outlined above, the NTA methodology has been developed to maximize comparability between countries. This has led to a flexible modelling approach where numerous data sources and methods are employed to estimate the underlying account items. Even though individual country data collections differ, all country teams strive to follow the standardised methodology, allowing detailed crosscountry comparisons. 
Although each individual item is calculated in a way that is specific to that item, the calculation of each item follows a general procedure. The first step is to calculate the aggregate benchmark. This is the aggregate amount of each parameter for the total economy (e.g. consumption, labour income, public age reallocations, and private age reallocations) derived from national accounts or equivalent data sources. This first step is crucial, as it enables all lower level account items to be consistent with the National Accounts.

The second step is to calculate an age pattern against which the aggregate benchmark is distributed. This is calculated using a combination of sample survey and administrative data. When data are available at the household level but not at the individual level, allocations must be made from the household to individual household members to generate the individual age profile. We utilise several approaches to allocate from the household, classified as follows:

(1) Regression approach: regression coefficients are used as weights to allocate from the household to the individual.

(2) Iterative method: A series of weights are used within an iterative algorithm to allocate from the household to the individual.

(3) Equivalence method: An NTA derived equivalence scale is used to allocate from the household to the individual.

(4) Equal benefit method: All individuals share the same allocation regardless of characteristics.

In the third step, selected age profiles are smoothed using a non-parametric smoother and are adjusted for sampling variation. The detailed procedure from the NTA manual is followed to unsure that data are not over smoothed.

The fourth step is to adjust the age patterns for missing populations. This is primarily an issue for residents of aged care in the Australian NTA.

Finally, the age profiles are constrained to meet the aggregate benchmark. A simple linear approach is adopted. 
Slightly different procedures and data sources are adopted for each of the NTA account items. In addition to demographic data and the Australian System of National Accounts, this project draws heavily upon Australian Bureau of Statistics (ABS) sample surveys, including the Household Expenditure Survey, Income and Housing Survey, Income Distribution Survey, and Survey of Disability, Ageing, and Carers. Published administrative data on programmatic expenditure are also used extensively.

Data for the six Australian NTAs calculated so far span an almost 30-year period. The construction of these accounts involved the collection, analysis, and general marshalling of a large number of information sources and, in some cases, these information sources were not entirely comparable over time. Over time, the household surveys conducted by the ABS have become increasingly comprehensive. Because of this, the Australian NTA estimates for the later years are improvements on those for the earlier years, although these improvements come at the cost of comparability. For example, earlier surveys did not include estimates of imputed rent or information on assets owned by households (excluding information on owner-occupied housing).

The increasing comprehensiveness of many of the household surveys conducted by the ABS has improved the Australian NTA estimates in another way as well. The Household Expenditure Surveys for 1993-94, 1998-99, 2003-04, and 2009-10 contain almost all the information needed to construct full sets of per capita age profiles for the Australian NTA. This was not the case for the household surveys for the earlier years. The 1988-89 Australian NTA estimates are based largely on the 1988-89 Household Expenditure Survey but this survey does not include information on the value of owner-occupied housing owned by households. This information was obtained, instead, from the 1990 Income Distribution Survey. The 1981-82 Australian NTA is based largely on the 1981-82 Income and Housing Survey but this survey does not include information on household expenditure, the effects of government benefits and taxes on household income, and the value of owner-occupied housing owned by households. Information on all of these is used in the construction of per capita age profiles in the Australian NTA. Given that this information is not included 
in the 1981-82 Income and Housing Survey, it was obtained from multiple other sources, in particular, the 1984 Household Expenditure Survey, the 1986 Income Distribution Survey, and ABS (1987).

Finally, the household surveys on which many of the per capita age profiles in the Australian NTA are based differ significantly in terms of the age at which individuals are top-coded. The 1981-82 Income and Housing Survey and the 1993-94, 2003-04, and 2009-10 Household Expenditure Surveys top-code age at 85 years and over. In contrast, the 1998-99 Household Expenditure Survey top-codes age at 75 years and over, while the 1988-89 Household Expenditure Survey top-codes age at 90 and over. This has implications for the comparability over time of the Australian NTA estimates for individuals aged 75 and over.

\section{Findings}

\section{Mature Age Labour Force Participation}

Before turning to the key NTA results, we briefly discuss recent changes in mature age labour force participation in Australia. We include data on labour force participation from 1980, the first year for which Australian NTA data are available.

As noted earlier, Australia has experienced an unprecedented growth in mature age participation since the start of this century. In the following graphs, we present labour force age participation rates for ages 55-59, 60-64, and 65+ for males (Figure 1) and females (Figure 2).

From the turn of the century, male labour force participation has increased significantly across all three age groups, but with the largest gains experienced by those aged 60-64. In 2000, about 47\% of 60-64 year olds were in the labour market compared with $63 \%$ today. Rates for those aged 55-59 increased by 8 percentage points and for the 65 and over group rates nearly doubled, albeit from a low rate. This rise in male participation follows a 20 year decline or stagnation between 1980 and 2000. For example, in $198081 \%$ of those aged 55-59 were in the labour market compared with $72 \%$ in 2000 . There was virtually no change for those in the oldest age 
category - with labour force participation constant at around $10 \%$ throughout the full period.

\section{<FIGURE 1 ABOUT HERE $>$}

In contrast, mature age female labour force participation grew throughout the full period (1980-2016), but with the speed of change hastening considerably after 2000 but slowing from 2010 onwards. In 1980 14\% of females aged 60-64 were in the labour market, compared with $21 \%$ in 2000 and $49 \%$ today. More recently, growth in mature age labour force participation for both males and females has levelled off.

\section{<FIGURE 2 ABOUT HERE>}

Even with rises in male labour force participation, differences in participation has closed considerably by gender for the two younger age groups (Figure 3). In 1980, among those aged 55-59 there was over a 50 percentage point gap between male and female labour force participation, compared with a 12 point gap today. For those aged 65 and over, the gap in participation by gender has remained constant throughout the period, indicative of the similar speed of growth in participation experienced by males and females.

\section{<FIGURE 3 ABOUT HERE $>$}

\section{Per Capita and Aggregate Consumption and Labour Income}

Given these significant improvements in mature age labour force participation, how have they been reflected in the Australian NTA? In this section, we present results from the Australian NTA standardised to 2009-10 dollars. For each parameter, we report results on a per capita basis (results averaged across individuals) and an aggregate basis (population-wide totals).

Figure 4 presents estimates of average per capita and aggregate consumption by single year of age from 1981-82 to 2009-10. Figure 5 replicates these estimates for labour income. 
Consistent with the international evidence (Lee and Mason, 2011b), it is clear that consumption is greater than labour income for younger and older Australians, while labour income is greater than consumption for working-aged Australians. It is also clear that with each successive time period, values of both consumption and labour income (all standardized to 2009-10 dollars) increase considerably. For example, in 1981-82, the key working ages consumed around $\$ 25,000$ per capita, compared with about $\$ 40,000$ for the same ages in 2009-10.

Total per capita consumption rises steeply to a first peak at around 25 years of age, falls gradually to a trough at around 35 years of age before rising gradually to a second peak at around 58 years of age, and then falls slightly in later life. This is relatively consistent across each year. Total consumption is comprised of both public and private consumption items, as discussed earlier. Briefly, to contextualize this result, the more detailed account items (not included here) show that private education consumption, as well as public education consumption (that is, consumption of publicly provided education services), are concentrated among younger Australians. In contrast, private health consumption and public health consumption (that is, consumption of publicly provided health services) are concentrated among older Australians. Other private consumption, which includes all private consumption apart from education and health (for example, food, clothing, rent, and so on), rises from birth to a first peak in the late $20 \mathrm{~s}$. It then falls but rises to a second peak in the late $50 \mathrm{~s}$, and then falls in later life. Other public consumption, which includes all public consumption apart from education and health (for example, consumption of such publicly provided services as defence and policing), has in these estimates largely been assigned equally to all ages.

\section{<FIGURE 5 ABOUT HERE>}

Given the large increases in consumption since the early 1980s, it is not surprising that returns to labour have also increased significantly for the working age population. 
Figure 5 presents per capita age profiles for total labour income, which includes two components, earnings and labour income for the self-employed (that is, that share of self-employment income that can be attributed to labour rather than capital). Viewed from an annual or cross-sectional perspective, total labour income begins to rise very steeply at around 15 years of age. It begins to plateau at around 30 years of age. Total labour income begins to fall very steeply from the mid-40s to 50 years of age across the years.

Despite the large increases for the majority of the working age population, for younger Australians in the labour market (under about age 20), there have been no real increases in labour earnings. This is likely due to the shift from full-time to parttime work among this age group. At the opposite end of the age spectrum, the opposite is the case, with large increases in mature age labour income as evident from the outward shift of the labour income profile. This is particularly noticeable between 2003-04 and 2009-10. How does this increase translate into changes in the life cycle deficit?

The Per Capita and Aggregate Life Cycle Deficit

As Figures 4 and 5 show, younger Australians consume while earning negligible amounts of labour income. A similar situation is found among older Australians, who have significant levels of consumption while earning only small amounts of labour income. Both younger and older Australians consume more than they earn in labour income. In contrast, Australians of prime working age earn more in labour income than they consume. This is described in more precise terms in Figure 6, which presents average per capita age profiles for the life cycle deficit, as well as aggregate age profiles.

\section{<FIGURE 6 ABOUT HERE>}

The per capita life cycle deficit reaches an initial peak in the mid-teens (as consumption rises steeply) before dropping (as labour income begins to rise very 
steeply). The life cycle deficit bottoms out between 30 and 50 years of age (as labour income plateaus), after which it begins to increase (as labour income begins to fall steeply). At around the mid-50s, the life cycle deficit returns to the deficit level of its initial peak. In general, the life cycle deficit increases in later life. As Figure 5 suggests, under about 25 years of age, consumption tends to be greater than labour income and the life cycle deficit is positive. A similar situation is found from the mid50s onwards. Between the ages of the mid-20s and mid-50s, labour income tends to be greater than consumption and the life cycle deficit is negative (or, there is a life cycle surplus).

Unsurprisingly, there are also some changes concerning which age groups are consuming more than they are producing. Specifically, the ages at which the life cycle deficit moves from positive to negative territory and vice versa have gradually increased over time.

Table 4: Age Entering and Exiting Surplus, 1981-82 to 2009-10.

\begin{tabular}{lll}
\hline Year & $\begin{array}{l}\text { Age Entering } \\
\text { Surplus }\end{array}$ & $\begin{array}{l}\text { Age Exiting } \\
\text { Surplus }\end{array}$ \\
\hline $1981-82$ & $19->20$ & $56->57$ \\
$1988-89$ & $21->22$ & $55->56$ \\
$1993-94$ & $23->24$ & $54->55$ \\
$1998-99$ & $23->24$ & $55->56$ \\
$2003-04$ & $23->24$ & $56->57$ \\
$2009-10$ & $24->25$ & $57->58$ \\
\hline
\end{tabular}

For example, in 1981-82 the age at which the life cycle deficit crosses into surplus territory is between 19 and 20, compared with between 24 and 25 in 2009-10. Similarly, the age at which the life cycle surplus turns to deficit moved from between 54 and 55 in 1993-94 to between 57 and 58 in 2009-10 (Table 4). Interestingly, for the earlier period (1981 to 1994), the age at surplus exit falls from 56 to 54 . This result is reflective of the declines and stagnation in labour force participation that occurred for males as discussed earlier. 
The existence of life cycle deficits among younger and older Australians raises the question: among these age groups, when labour income is less than consumption, how is this consumption funded? The answer to this question lies in the reallocation of resources among age groups, in which the life cycle surplus among Australians of prime working age is a resource that is used to fund the life cycles deficits among younger and older Australians. Reallocation of resources among age groups can occur through a variety of mechanisms: private transfers (for example, parents purchasing goods and services for their children), public transfers (for example, public age pensions and publicly provided education and health services), asset income, and saving.

Figure 7 displays the funding components of the life cycle deficit on a per capita and aggregate basis for 2009-10. For younger Australians, to about age 10, public transfers are roughly equal to private intra-household transfers. In the teenage years, private intra-household transfers are larger than public transfers.

Not surprisingly, mature age Australians also receive large public transfers. They also receive significant amounts from private asset income which includes imputed rent from owner-occupied housing and for some years a small amount of dissaving. For those in the prime working ages, there is a strong surplus of private asset income, with an offsetting deficit of public transfers, private intra-household transfers, and private saving.

\section{<FIGURE 7 ABOUT HERE $>$}

As discussed earlier, Australia has experienced an unprecedented growth in mature age labour force participation since the turn of this century. This has led to large increases in mature age labour income, particularly between 2003-04 and 2009-10, which in turn has translated into a gradual increase over time in the age at which the life cycle deficit moves from negative to positive territory. 
These shifts have implications for the position in which mature age Australians find themselves as they face and experience retirement, as well as for the age reallocations in Australia that revolve around retirement and ageing. Between 2003-04 and 200910 , the annual per capita labour income received by those aged $55+$ grew by $\$ 6,703$ (in 2009-10 dollars). Some of this growth in labour income was used to fund a $\$ 1,974$ increase in per capita private consumption by this age group. The vast bulk of this growth, however, seems to have been saved by those aged 55+. Per capita private saving by this age group increased by $\$ 6,560$.

While private consumption rose, so did public consumption. Per capita public consumption by those aged $55+$ increased by $\$ 1,534$. Public consumption is both a kind of consumption by individuals and a transfer from the public sector to individuals, so public consumption is both a component of consumption and a component of public transfers. Because of changes in other components of public transfers, total per capita public transfers received by those aged 55+ increased by $\$ 1,224$ on average, which is less than the increase experienced in public consumption. Public transfers received by people aged 55-64 fell, however, while those received by people aged $65+$ rose. Some of these changes were funded by a deterioration in the fiscal gap. Between 2003-04 and 2009-10, public saving switched from positive territory (saving) to negative (dissaving), with the portion of this switch borne by those aged 55+ (in their role as taxpayers) amounting to a fall in per capita public saving of $\$ 2,697$. Only comparatively small changes were evident in per capita private inter-household transfers, private intra-household transfers, private asset income, and public asset income.

Cohort Comparisons of Labour Income and Consumption Trajectories and the Life Cycle Deficit

An important limitation of the results presented above is that they are cross-sectional in nature. Using the multiple cross-sections of NTA data, it is possible to construct cohort trends across each parameter. That is, it is possible to view trajectories of people born in the same years across time as they age. As data are available over a 28year time frame from 1981 to 2009 , the cohort data show 28-year segments of 
people's lives, for example, as they age from 0 to 28 , from 7 to 35 , and so on. In each of the following cohort graphs (Figures 8, 9, and 10), we compare the 2009-10 crosssectional estimate of labour income, consumption, and the life cycle deficit with the cohort estimate for persons ageing during the 28 years from 0 to 28 , through to 57 to 85 years.

Cohort results across labour income and consumption reinforce the cross-sectional finding that more recent cohorts tend to fair better with respect to their consumption and labour income than earlier cohorts. This is particularly the case for mature aged people, lending further support to the role of increased mature age labour force participation over this time.

While, in the cross-sectional analysis, labour income rises rapidly with age to plateau in the early 30s, the cohort analysis shows the more conventional view of labour income rising across the life cycle to about age 50. The interpretation of this difference is that changes in labour income tend to be cross-sectional, raising the incomes of people of different ages at the same time.

Interestingly, the cohort trajectories of consumption rise considerably faster across the different age groups than the cross-sectional trajectories. Less variability is shown in the cohort estimates of the life cycle deficit. Although the age at entry into surplus territory is roughly consistent between the cross-sectional and cohort estimates, this is not the case later in the life course when individuals cross back into deficit. Earlier cohorts cross into deficit territory at an earlier age when compared to later cohorts, and indeed when compared to the cross-sectional estimate. This lends further support to the impact of increasing mature age participation on the life cycle deficit.

\section{<FIGURES 8, 9, AND 10 ABOUT HERE>}

These cohort data also enable us to view the lifetime trajectories of different cohorts at labour market exit age in more detail. With increasing mature age participation and 
wage growth, how are people of labour market exit age faring now compared to in the past?

In the following table and figure, we compare two cohorts of people: one group born in 1932-33 and a second group born in 1948-49 (Table 5). The slight discord in ages is due to the timing between the Household Expenditure Surveys ( 7 and 5 years for cohort 1; 5 and 6 years for cohort 2). Both groups age from 50 to 60 over the respective periods. This age range is chosen for two reasons. Firstly, there is a significant decrease in labour force participation across this age range. Secondly, as shown above the age at which the life cycle deficit exits the surplus years is contained in this range. Thirdly, in Australia, the preservation age (year at which you can legally access your superannuation account) is 55 for these cohorts (born before 1960), the midpoint of the age range.

\section{Table 5: Cohort Groups and Ages by Year}

\begin{tabular}{lllr}
\hline Cohort 1 & & & \\
\hline Years Passed & \multicolumn{1}{l}{ 0 } & \multicolumn{1}{l}{ 7 } & \multicolumn{1}{l}{. } \\
Year Born & $1981-82$ & $1988-89$ & $1993-94$ \\
1933 & 49 & 56 & 61 \\
1932 & 50 & 57 & 62
\end{tabular}

\begin{tabular}{lllr}
\hline \multicolumn{1}{l}{ Cohort 2 } & & & \\
\hline Years Passed & \multicolumn{1}{l}{ 0 } & \multicolumn{1}{l}{5} & \multicolumn{1}{l}{6} \\
Year Born & $1998-99$ & $2003-04$ & $2009-10$ \\
1949 & 50 & 55 & 61 \\
1948 & 51 & 56 & 62 \\
\hline
\end{tabular}

Results in Figure 11 show that those born in the later cohort had significantly higher labour income compared to the earlier cohort. This persists throughout the entire period, with the later cohort having much higher earnings at age 50 through to age 60 (Panel A). Moreover, the decline in labour income with increasing age is attenuated in later cohorts (Panel B). Once more, these results are indicative of the considerable increases in labour force participation during this period, particularly for women. 


\section{Discussion and Conclusions}

The goal of this paper has been to examine the shifts in the life cycle deficit and its constituent components over the last 30 years - a period characterised by considerable labour market change, including a significant increase in mature age labour force participation. To achieve this goal, we produced estimates of the full NTA account items for 1981-82, 1988-89, 1993-94, 1998-99, 2003-04, and 2009-10.

\section{Key Findings}

For all years, it is clear that total consumption is greater than labour income for younger and older Australians, while labour income is greater than consumption for prime-aged Australians. This translates into a life cycle deficit which is positive for younger and older Australians. This finding is consistent across the NTA countries as a general principle (Lee and Mason, 2011b).

With a 30-year time horizon, it has been possible to identify changes in the ages at which individuals consume more than they are producing. The ages at which the life cycle deficit moves from positive to negative territory and vice versa have gradually increased over time. In 1981-82, the age at which the life cycle deficit crosses into surplus territory is between 19 and 20 compared with between 24 and 25 in 2009-10. Similarly, the age at which the life cycle surplus turns to deficit moved from between ages 54 and 55 in 1993-94 to between 57 and 58 in 2009-10. Supporting these crosssectional estimates, the cohort analysis shows younger cohorts crossing into deficit at a later age than older cohorts.

This finding reflects the rapid increase in mature age labour force participation that has occurred in the first decade of the $21^{\text {st }}$ century in Australia. Indeed, results presented here show that the majority of the increase over the last 30 years in male mature age labour force participation occurred in the first decade of this century. For example, males aged 60-64 years had a labour force participation rate of around 50\% during the entire $1982-2002$ period, but this increased to $62 \%$ during the 10 -year period to 2012. For females too, there was a strong increase in the same period, but this increase follows a long, 30-year trajectory of increases. This rapid increase in 
labour force participation has thereby translated into an increase in the labour income of mature age Australians and a resulting shift outward of the crossover age for the life cycle deficit.

Over this 30-year period, the value (in 2009-10 dollars) of both consumption and labour income has increased significantly, albeit at different rates across the age distribution. Despite the large increase for the majority of the working age population, for younger Australians in the labour market (under about age 20), there have been no real increases in labour earnings as they have moved from full-time employment to a combination of study and part-time employment or to study alone. At the other end of the age spectrum, the opposite is the case, with large increases in mature age labour income as evident from the outward shift of the labour income profile. This is particularly noticeable between 2003-04 and 2009-10. This corresponds with the large increase in mature age participation over this period as noted above.

The growth in mature age labour force participation since the turn of this century has led to large increases in mature age labour income, the most important effect of which appears to have been a substantial increase in private saving by mature age Australians. These shifts have encouraging implications for the position in which mature age Australians find themselves as they face and experience retirement. Firstly, these shifts suggest that mature age Australians are prepared to fund their increasing longevity at least in part by working longer. Secondly, these shifts suggest that when mature age Australians increase their labour force participation, much of the additional labour income they receive is saved. As a result, increased mature age labour force participation does not only help to fund increases in current consumption, it also builds up assets that can be used to fund consumption later in life.

This raises the question: why has Australia's levels of mature age participation risen so quickly from early this century? There is strong international evidence that the design of the tax-transfer and retirement incomes systems drives mature age labour force participation (Gruber and Wise, 2002). Indeed, there have been numerous changes to retirement incomes policies in Australia that may have encouraged later life employment during this period (see Swoboda, 2014, for a detailed overview of changes). Like many countries, in Australia there is evidence that the tax-transfer 
system is complex and acts as a disincentive for mature age people to work (Temple and Adair, 2012). Reforms in recent decades have not necessarily made the system simpler, but may have influenced labour force participation. Declaring superannuation income from a taxed source as tax-free for people aged over 60 years is one example of such reform. Another example is the Work Bonus scheme, which sought to encourage Age Pensioners to maintain links with the workforce by disregarding an amount of earned income when calculating assessable income for Age Pension purposes. More generally, recent tax reforms have increased the tax-free threshold, with the aim of encouraging more people (not just older Australians) into the workforce. The Federal Age Discrimination Act was also passed into law in 2004 with one aim being to protect older workers from discrimination. In the immediate future, the Federal Government is increasing the Age Pension access age from 65 to 67 years, at a rate of six months every two years, beginning in July 2017.

However, there are many reasons why participation by mature age people in the labour force could have been expected to increase, with or without government intervention. At the turn of this century, when male mature age labour force participation was low, McDonald and Kippen (1999) hypothesised an increase in participation for numerous reasons, including that:

- In the future, jobs may be less physically demanding.

- The next generation of mature age workers started formal employment later in life and may therefore conclude work later in life.

-More people will be self-employed and have greater autonomy over their work.

-The next generation will be healthier and more aware of the long years that remain in their lives.

- The people in the 55-64 year age group had their children at a later age and their children will stay financially dependent for more years.

-Simultaneously, mature age people may have financial responsibilities for their own parents.

- The baby-boomer generation has expectations of higher living standards in retirement than their parents. The Age Pension alone may not be sufficient for these higher living standards and the years of retirement income will be longer.

- In the 1990s, participation in the labour force when people were between 55 and 64 years was low because of the decline in the manufacturing industry in the 1980s. Over 
time, this generation moves into the older ages replaced by people less affected by shake-outs in manufacturing industry.

-Because of changes in female participation in the labour force, the partners of 55- 64 year old males will be more likely to be working in the future and thereby not encouraging their partner to retire.

Although participation rates have risen, the age of exit from the life cycle surplus (working ages) into the life cycle deficit is likely to remain in the late 50s. This raises the question: among age groups, when labour income is less than consumption, how is this consumption funded? In the NTA, reallocation of resources among age groups can occur through private transfers, public transfers, and asset-based reallocations. Results show considerable differences in the reallocations by age. Younger Australians receive large public transfers in addition to private intra-household transfers. For those in the prime working ages, there is a large surplus of private asset income, with an offsetting deficit of public transfers, private intra-household transfers (primarily to children), and private saving. Mature age Australians also received large public transfers, as well as significant amounts from private asset income. This significant flow of asset income received by older Australians runs counter to stereotypes about older people being overly reliant on public financing for their ongoing wellbeing. It also emphasises the significant role that owner-occupied housing plays in reducing the potential level of public transfers for older people.

Nonetheless, in the future, the sharp increase in the number of older people places these reallocation mechanisms under stress, particularly as the baby-boom generation, surviving longer, moves into the high-cost ages of 80 years and over. As the proportion of older Australians in the population rises and the proportion of prime working age Australians falls, the life cycle deficit in need of funding increases in relative terms just as the life cycle surplus used to fund this deficit decreases in relative terms.

Life expectancy for Australian men at age 60 has increased from 15 years in 1970-72 to 24 years in 2013-15. The question for Australian men has been whether the additional nine years is simply added to years of retirement or whether some of it has been used to extend employment. It is clear from the analysis here that, in the decade 
from 2000 to 2010 , many opted to continue working. The same is even more the case for women. However, in the past five to six years, especially for men, the increase in participation at older ages has virtually ceased and at a level well below older age participation in New Zealand. Continued labour force participation carries many benefits for the individual, for employers and for government. Individuals experience an increase in income, a higher accumulation of superannuation, potentially better health and, depending upon the nature of the work, a sense of satisfaction and contribution. Employers faced with skilled labour shortages are able to utilise an older labour force where, again depending on the nature of work, there is strong evidence that older persons are highly effective workers. For governments, extended labour force participation increases tax revenue, reduces age pension costs and potentially health care costs. So there is a policy question as to how older age participation can be stimulated at a time when increases in participation have slowed.

The future trajectory of mature age labour force participation and forecasts of the life cycle deficit are future research priorities for the Australian NTA project. 


\section{Acknowledgements}

This Australian study forms part of a large international effort to construct National Transfer Accounts. Further information is available at: www.ntaaccounts.org. Funding for the development of the Australian NTA has been provided by the National Health and Medical Research Council and the Australian Research Council through an Ageing Well, Ageing Productively Research Program grant (ID 401158) and the Australian Research Council's Centre of Excellence in Population Ageing Research (CE1101029). Funding for this study has also been made available by the Australian Department of Social Services. Numerous ABS sample survey data sets were made available to the authors through the Australian Bureau of Statistics (ABS) and Australian Vice Chancellors' Committee (AVCC) agreement. The opinions expressed herein do not reflect those of the ABS or AVCC.

\section{References}

ABS. 1987. 1984 Household Expenditure Survey, Australia: The Effects of Government Benefits and Taxes on Household Income. Cat. No 6537.0. Australian Bureau of Statistics: Canberra.

ABS. 2017. Labour Force Status by Age, Greater Capital City and Rest of State. Cat. No. 6291.0.55.001. Australian Bureau of Statistics: Canberra.

Gruber, J and Wise, D. 2002. Social Security Programs Around the World: Micro Estimation. NBER Working Paper No. 9407, National Bureau of Economic Research.

Lee, R., Mason, A. 2011a. Generational Economics in a Changing World. Population and Development Review 37(S1): 115-142. 
Lee, R., Mason, A. 2011b. Population Aging and the Generational Economy: A Global Perspective. Edward Elgar, Cheltenham, UK.

McDonald, P., and Temple, J. 2010. Immigration, Labour Supply and Per Capita Gross Domestic Product: Australia 2010-2050. Department of Immigration and Citizenship: Canberra.

McDonald, P., Kippen, R. 1999. Ageing: The Social and Demographic Dimensions, in Policy Implications of the Ageing of Australia's Population. Productivity Commission: Canberra.

Rice, J. M., Temple, J., and McDonald, P. 2014. National Transfer Accounts for Australia: 2003-04 and 2009-10 Detailed Results. ARC Centre of Excellence in Population Ageing Research and Crawford School of Public Policy, Australian National University. http://www.cepar.edu.au/media/134354/nta_report_2014.pdf.

Swoboda, K. 2014. Major Superannuation and Retirement Income Changes in Australia: A Chronology. Research Paper Series 2013/2014, Parliament of Australia: Canberra.

Temple, J., and Adair, T. 2012. Barriers to Mature Age Employment: Final Report of the Consultative Forum on Mature Age Participation. Department of Employment: Canberra.

Temple, J., and McDonald. P. 2008. Is Demography Destiny? The Role of Structural and Demographic Factors in Australia's Past and Future Labour Supply. Journal of Population Research 25(1): 29-49. 
United Nations (UN). 2013. National Transfer Accounts Manual: Measuring and Analysing the Generational Economy. United Nations: New York.

\section{Correspondence}

Associate Professor Jeromey B. Temple, Melbourne School of Population and Global Health, University of Melbourne, Melbourne, VIC, 3010, Australia. Email: Jeromey.Temple@unimelb.edu.au. Ph:+61 390363300. 
Table 1: Economic Life Cycle Input Parameters for the Australian National Transfer Accounts.

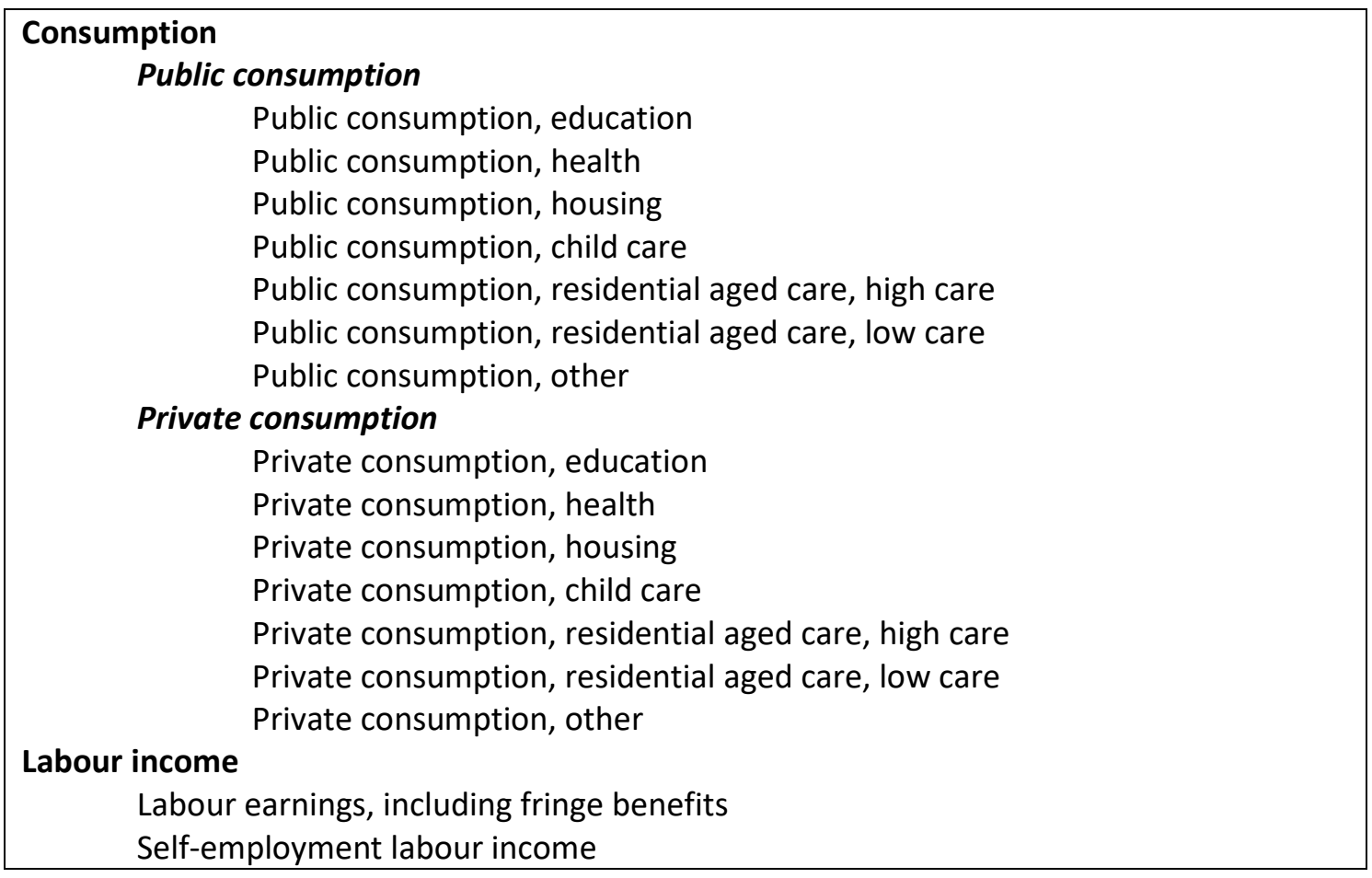

Table 2: Public Age Reallocation Input Parameters for the Australian National Transfer Accounts.

Public transfers

Public transfers, inflow

Public transfers, education, inflow

Public transfers, health, inflow

Public transfers, housing, inflow

Public transfers, child care, inflow

Public transfers, residential aged care, high care, inflow

Public transfers, residential aged care, low care, inflow

Public transfers, social protection targeted at the elderly, inflow

Public transfers, social protection targeted at the prime-aged, inflow

Public transfers, social protection targeted at the young, inflow

Public transfers, social protection, other, inflow

Public transfers, other in-kind, inflow

Public transfers, other cash, inflow

Public transfers, outflow

Income taxes levied on individuals

Income taxes levied on enterprises

Employers' payroll taxes

Taxes on property, corporations

Taxes on property, households

Taxes on property, unincorporated businesses

Goods and services tax (GST)

Other taxes on the provision of goods and services

Taxes on the use of goods and performance of activities 
Other transfers from private to public

Public transfers, deficit, outflow

Public asset-based reallocations

Public asset income

Public property income

Public property income, inflow

Public property income, outflow

Public capital income

Public saving

Table 3: Private Age Reallocation Input Parameters for the Australian National Transfer Accounts.

Private transfers
Private inter-household transfers
Private inter-household transfers, inflow
Private inter-household transfers, outflow
Private intra-household transfers
Private intra-household transfers, inflow
Private intra-household transfers, outflow
Private asset-based reallocations
Private asset income
Private property income
Private property income, inflow
Private property income, corporations, inflow
Private property income, households, imputed interest,
Private property income, households, other, inflow
inflow property income, outflow
Private property income, corporations, outflow
Private property income, households, consumer credit,
Private property income, households, other, outflow
Private saving
Private capital income
Private capital income, corporations (but not NPISHs)
Private capital income, owner-occupied housing
Private income, share of mixed income


Figure 1: Male Labour Force Participation, 1980-2016

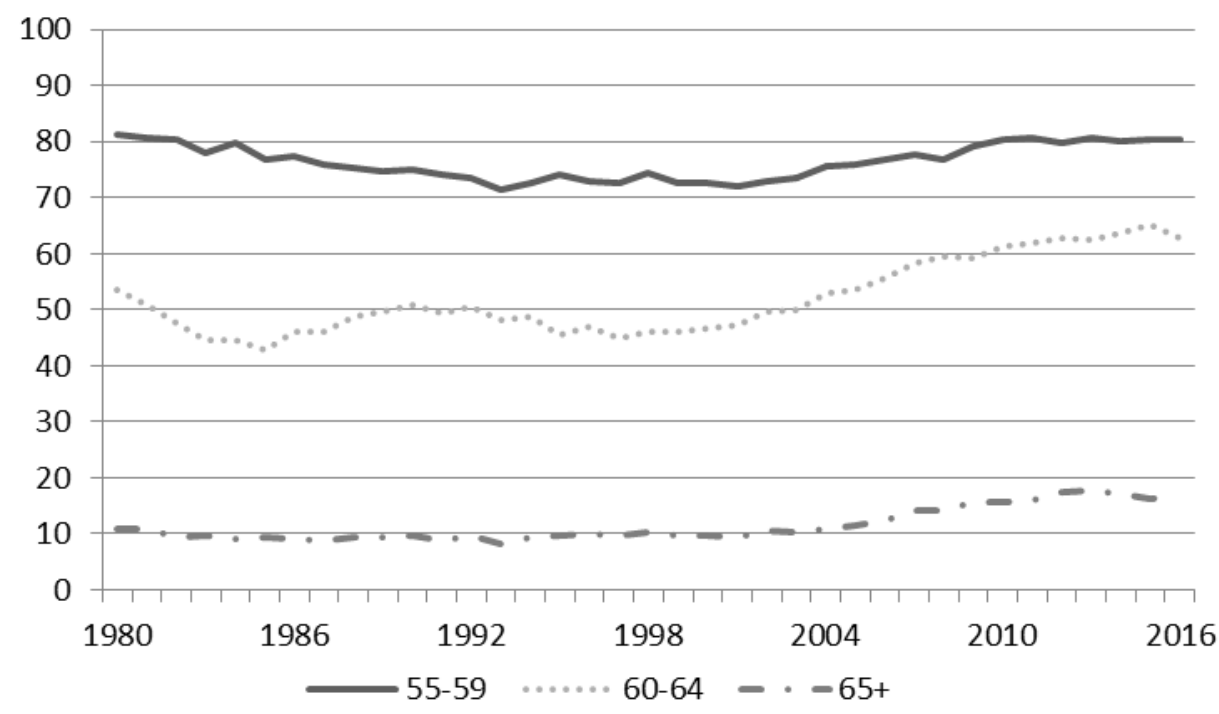

Source: ABS (2017). Notes: Rates at June of each year.

Figure 2: Female Labour Force Participation, 1980-2016.

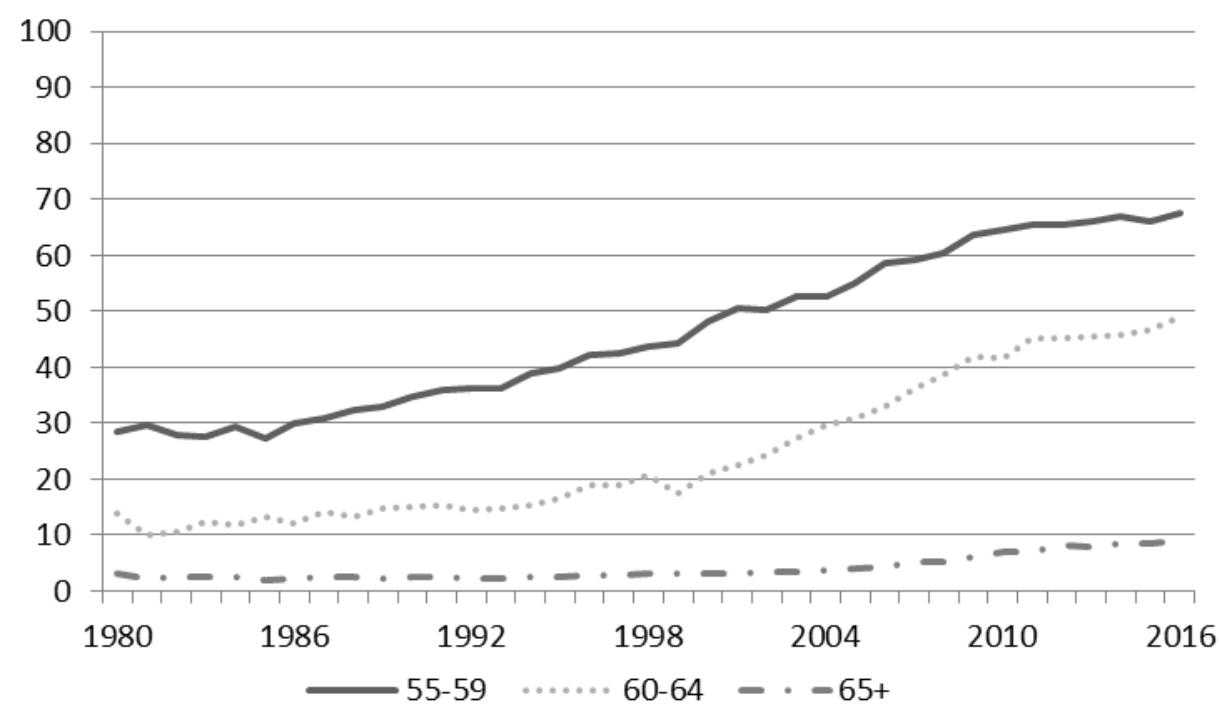

Source: ABS (2017). Notes: Rates at June of each year. 
Figure 3: Gender Gap in Mature Age Labour Force Participation

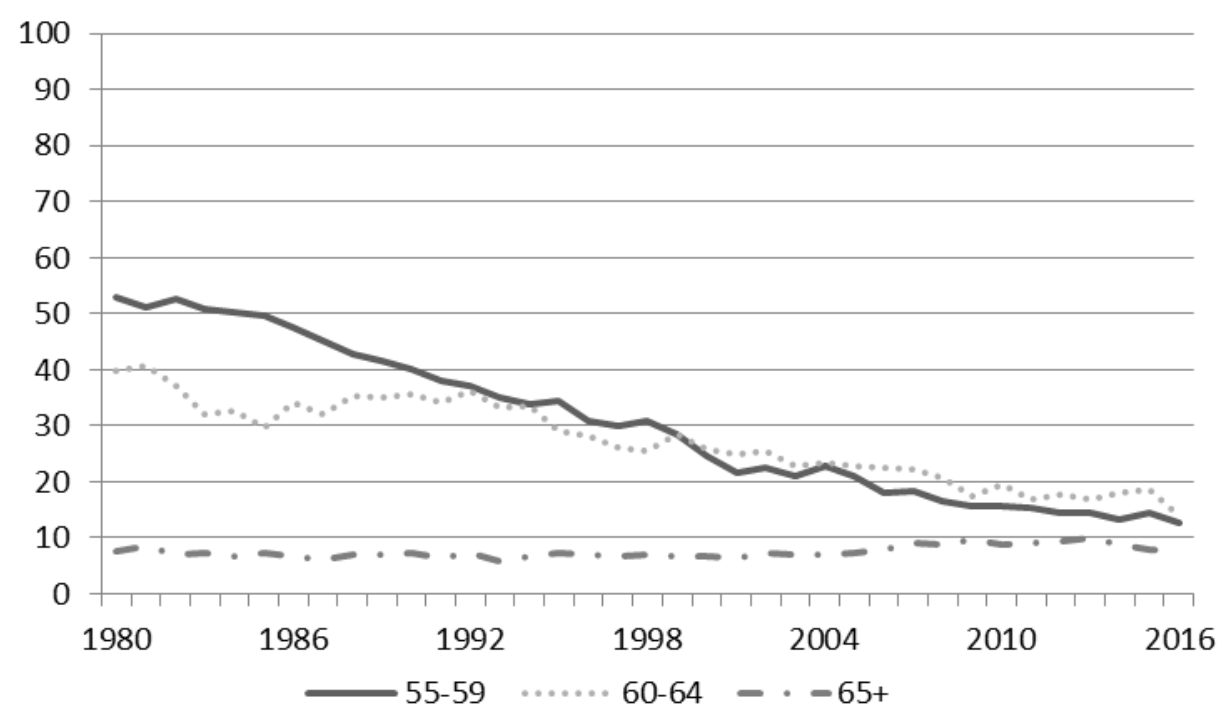

Source: Authors calculation from ABS (2017). Notes: Rates at June of each year. 
Figure 4: Per Capita and Aggregate Consumption, 1981-82 to 2009-10.

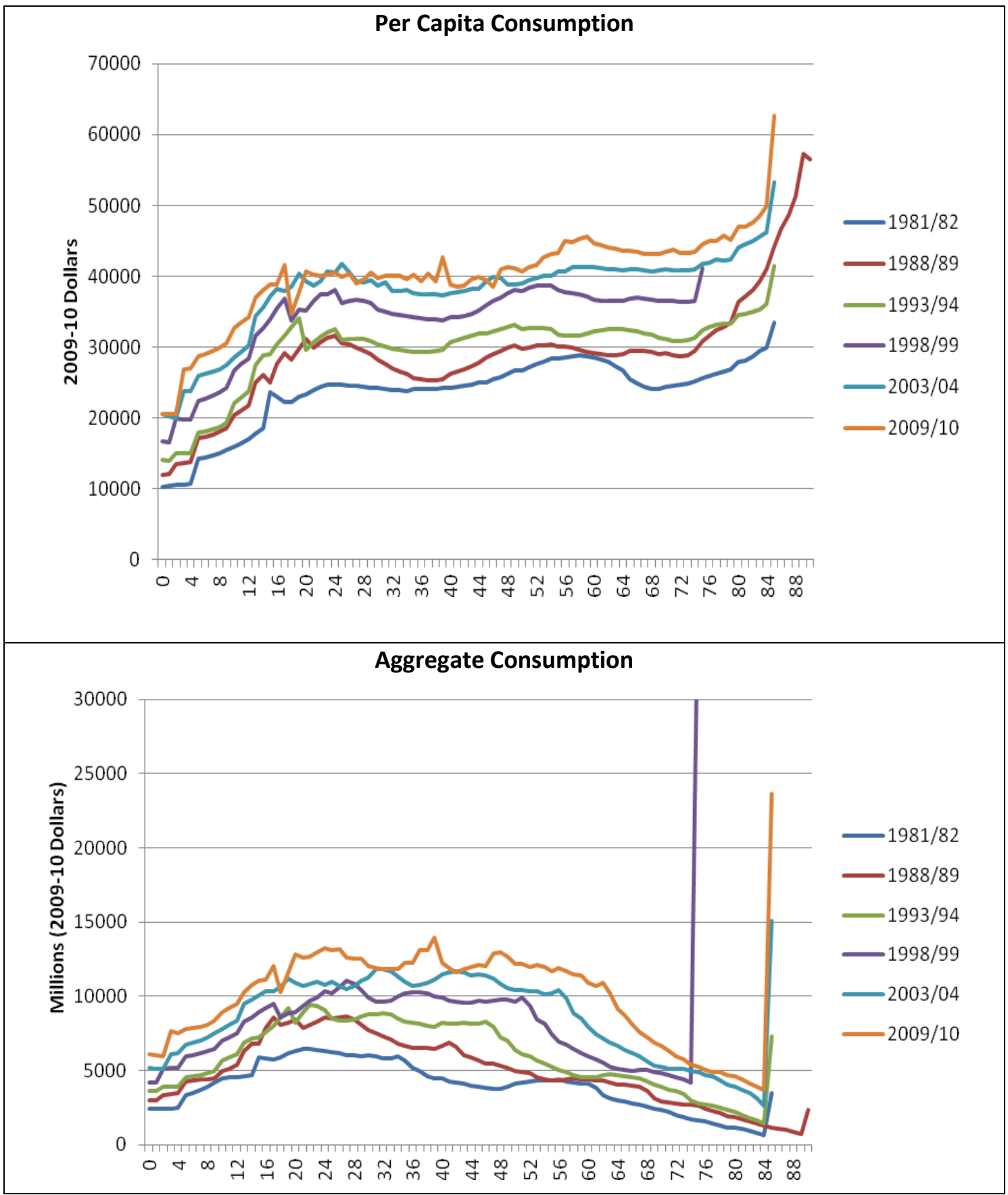

Note: The spikes at ages 75,85 , and 90 in these and subsequent graphs are due to the fact that all persons aged $75+, 85+$, and $90+$ are included together - due to the age confidentialisation for different years. 
Figure 5: Per Capita and Aggregate Labour Income, 1981-82 to 2009-10.

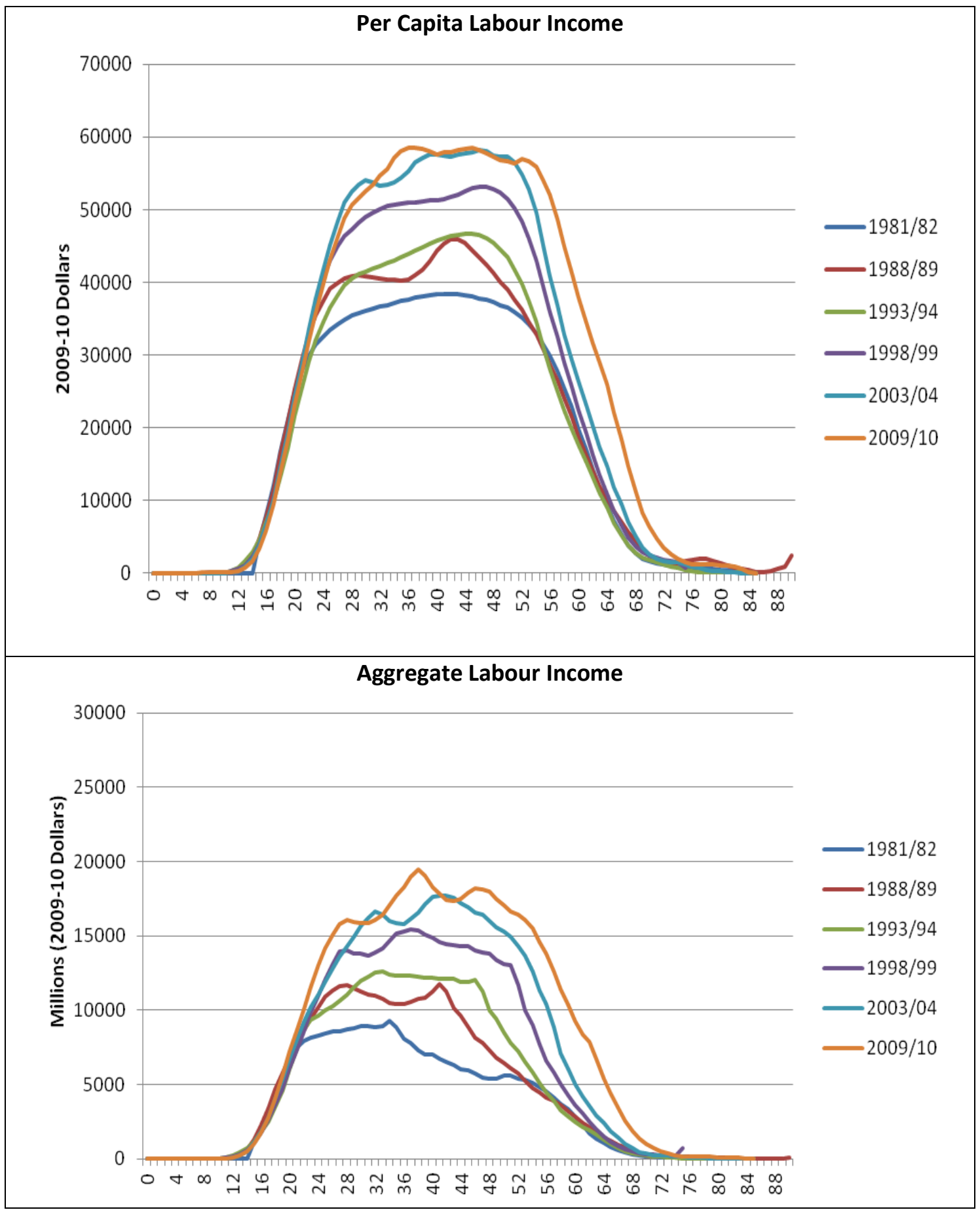


Figure 6: Life Cycle Deficit, 1981-82 to 2009-10.

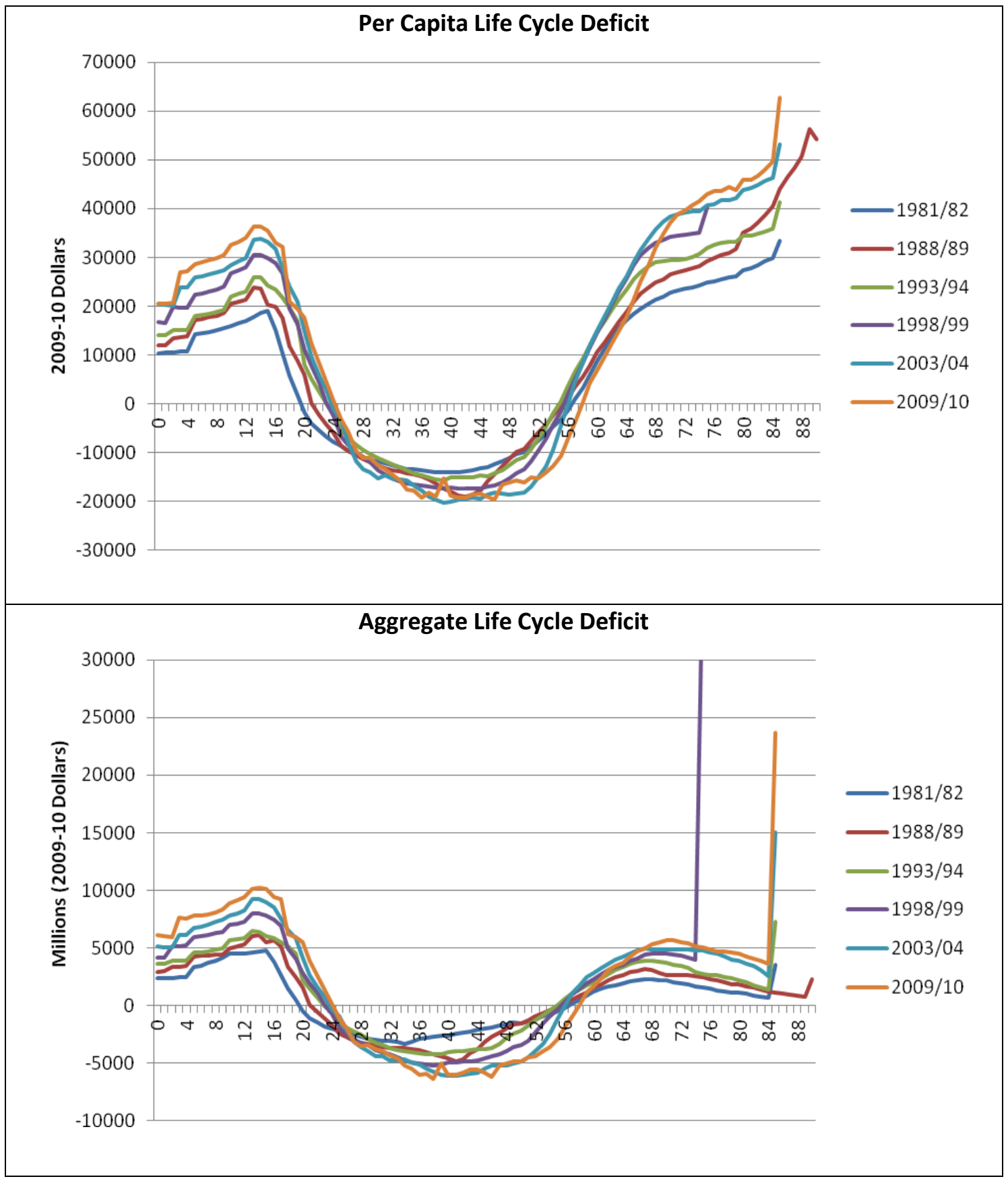


Figure 7: Funding the Life Cycle Deficit, 2009-10.

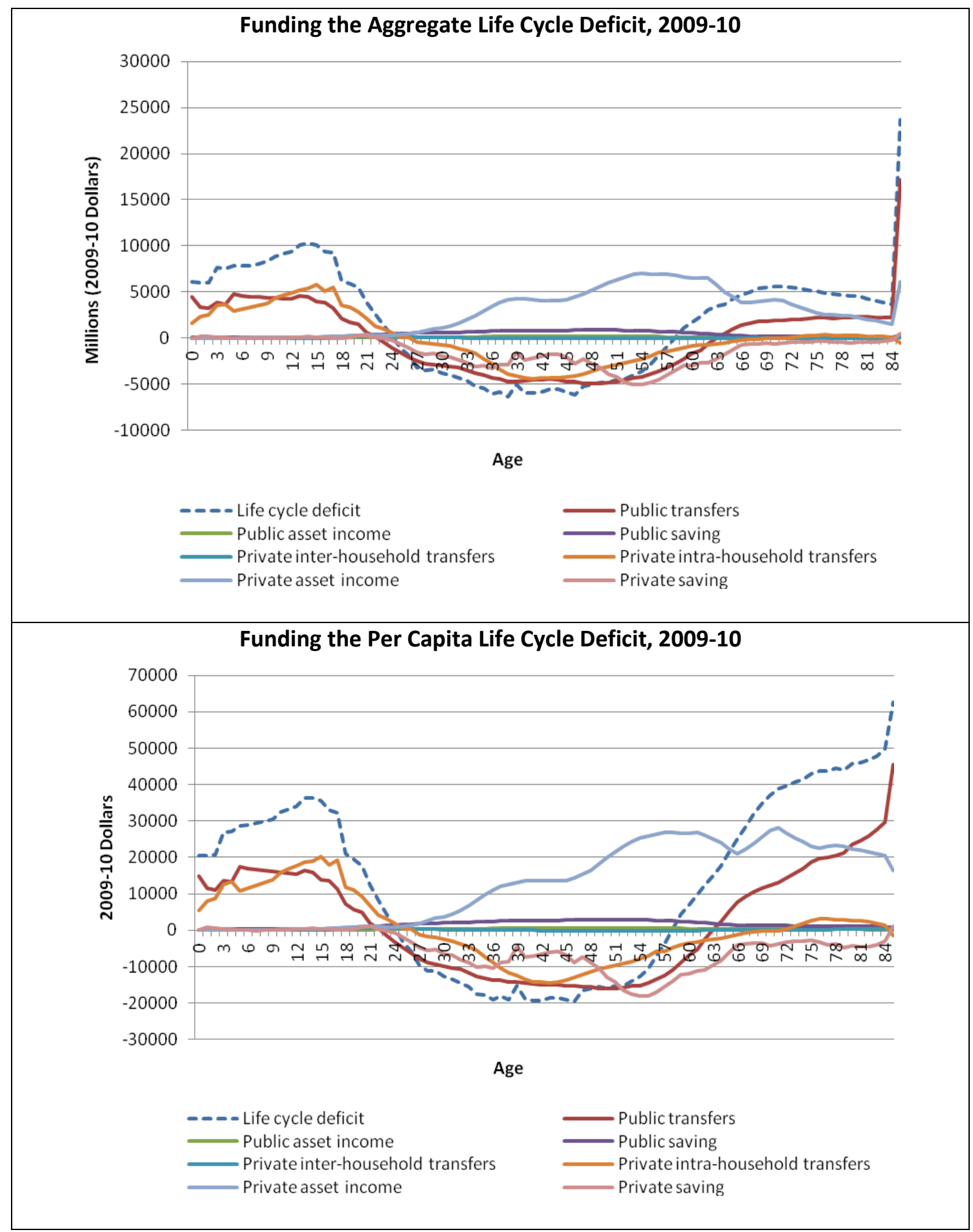


Figure 8: Cohort Trajectories of Labour Income.

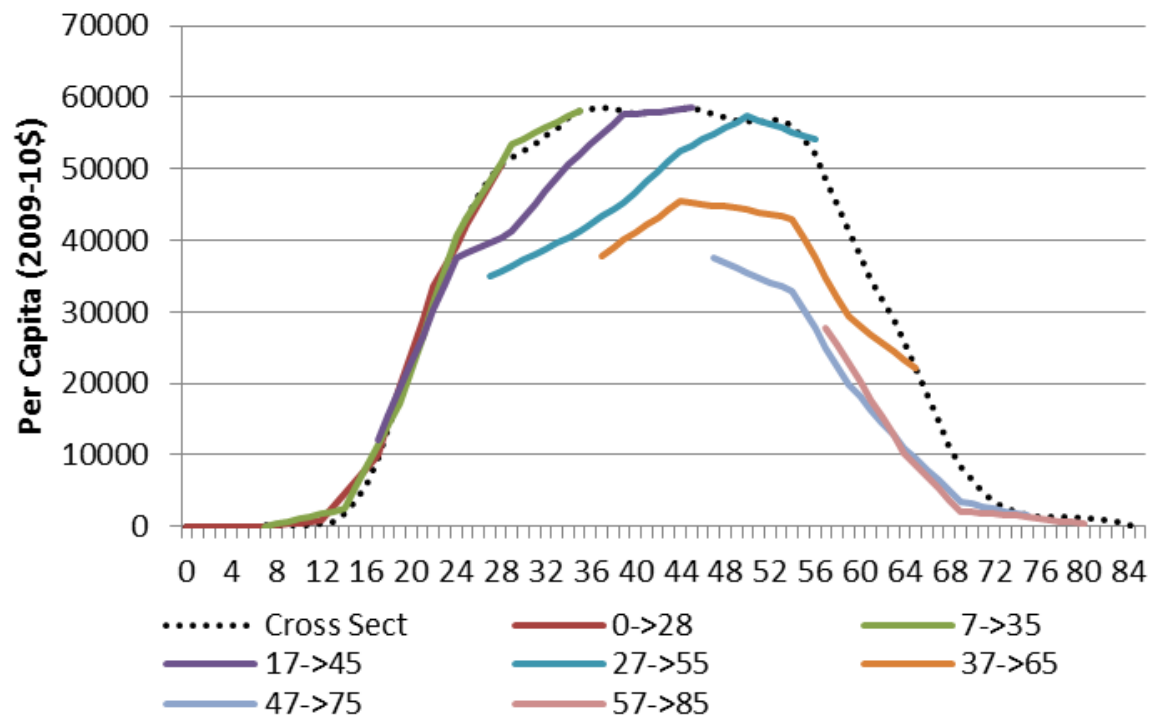

Figure 9: Cohort Trajectories of Consumption.

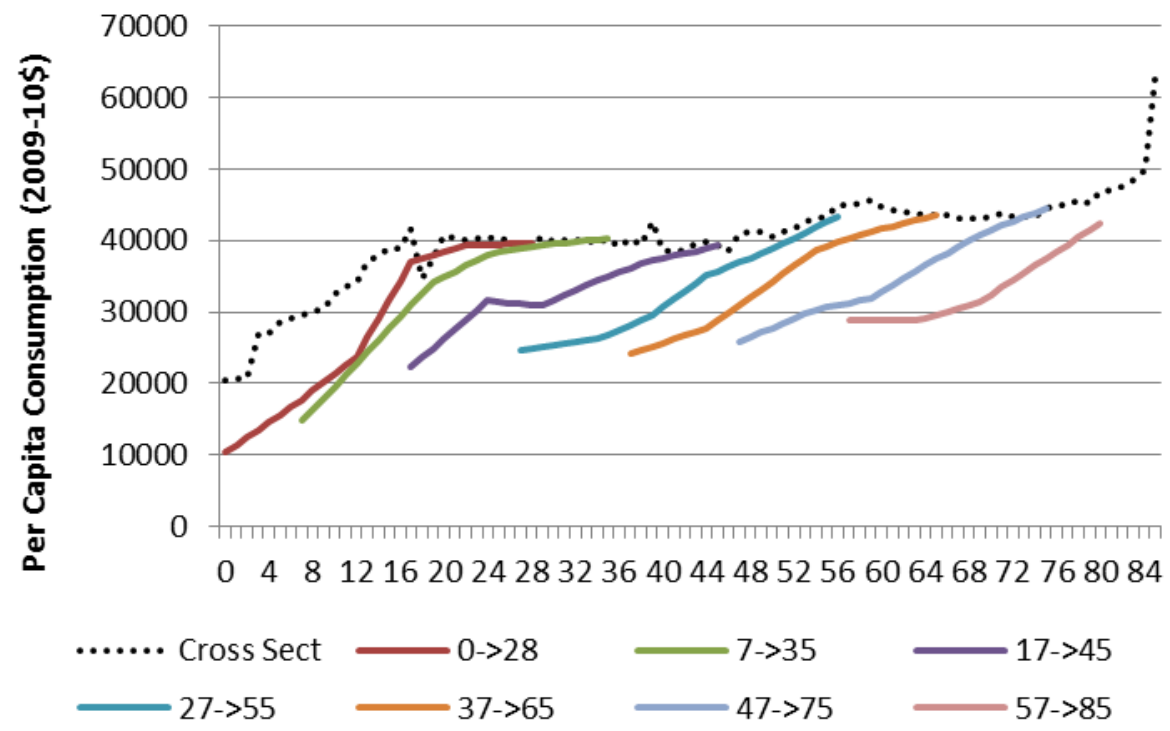


Figure 10: Cohort Trajectories of the Life Cycle Deficit.

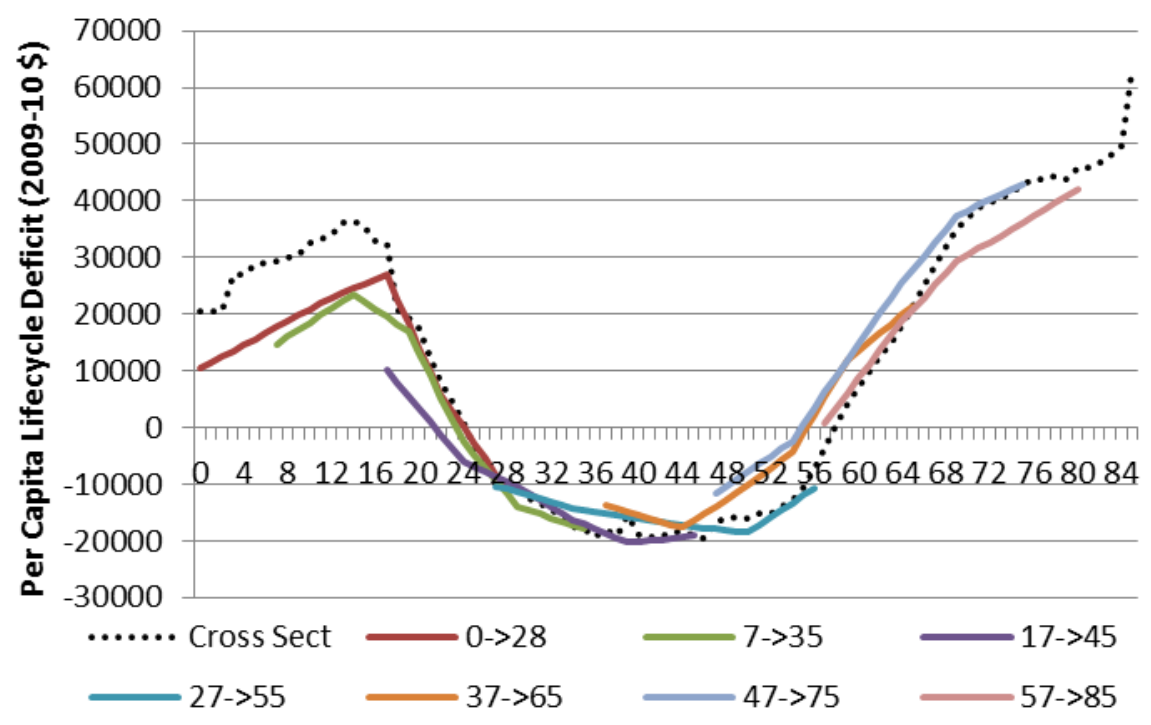


Figure 11: Labour Income and Labour Income Growth, Selected Cohorts.

Panel A: Labour Income

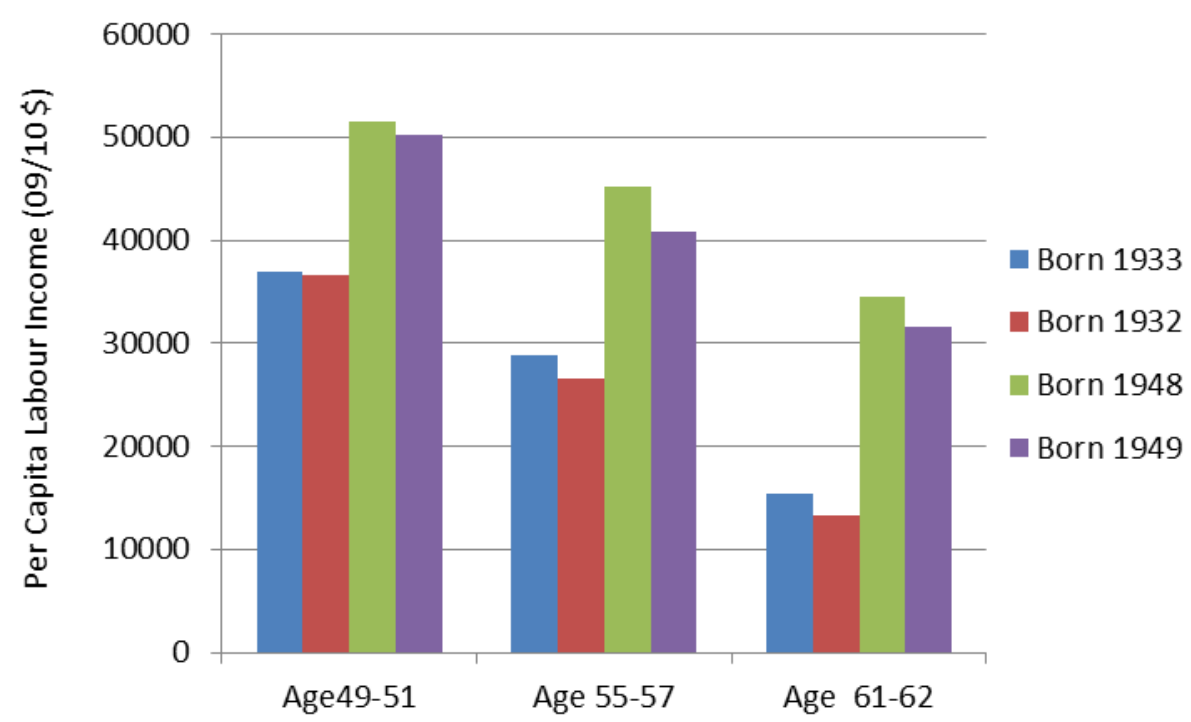

Panel B: Labour Income Growth

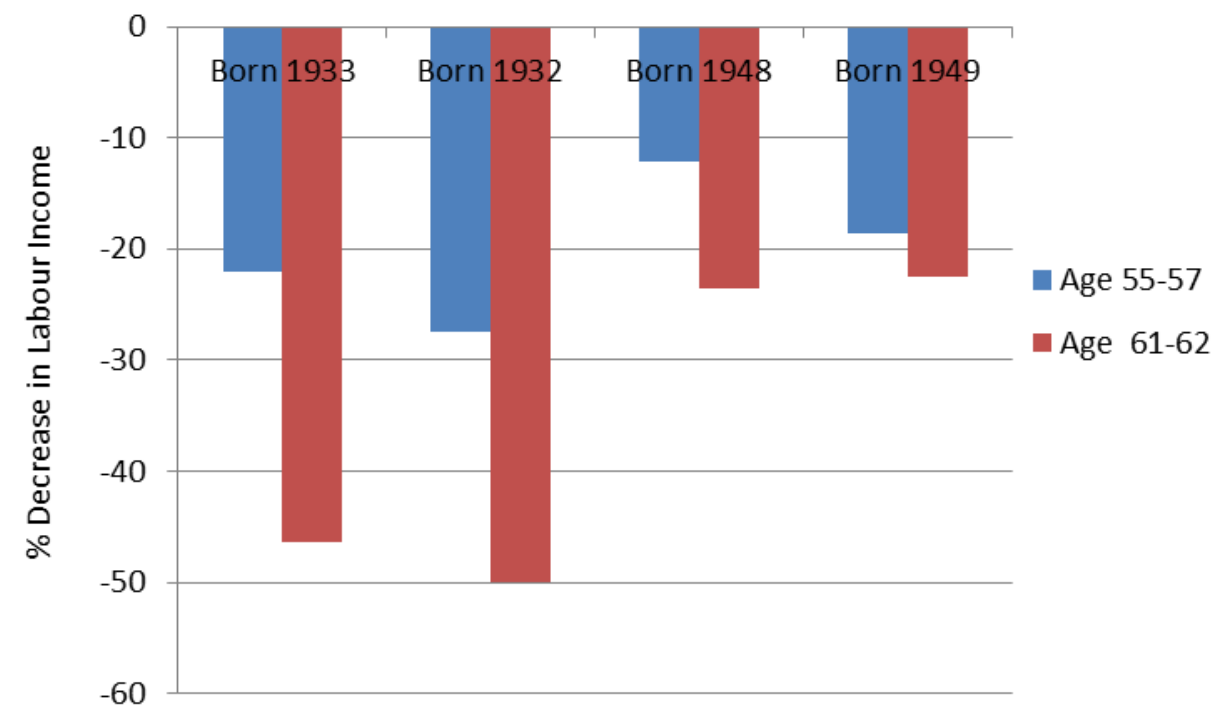




\section{University Library}

\section{- M M N E R VA A gateway to Melbourne's research publications}

Minerva Access is the Institutional Repository of The University of Melbourne

Author/s:

Temple, JB;Rice, JM;McDonald, PF

Title:

Mature age labour force participation and the life cycle deficit in Australia: 1981-82 to 2009-10

Date:

2017-12-01

Citation:

Temple, J. B., Rice, J. M. \& McDonald, P. F. (2017). Mature age labour force participation and the life cycle deficit in Australia: 1981-82 to 2009-10. Journal of the Economics of Ageing, 10, pp.21-33. https://doi.org/10.1016/j.jeoa.2017.08.001.

Persistent Link:

http://hdl.handle.net/11343/253835 